\title{
A democracia representativa no Brasil: problemas e questionamentos
}

\section{Audálio José Pontes Machado ${ }^{1}$}

1 Mestrando em Ciência Política pela Universidade Federal de Pernambuco (UFPE). Graduado em Ciência Política com ênfase em Relações Internacionais pela UFPE, Brasil. E-mail: audaliomachado@gmail.com

RESUMO: O objetivo deste trabalho é trazer à pauta uma discussão abarcando a literatura recente sobre representação política e todas as suas vertentes, focando especificamente no caso brasileiro. Em termos metodológicos, o artigo é majoritariamente teórico, buscando coadunar pensamentos diversos acerca do mesmo tema: representação. As conclusões apontam que a democracia representativa brasileira tem uma série de problemas, mas que muito já foi alcançado desde a redemocratização nos anos oitenta, sendo necessária, portanto, mais atenção para a relação entre representantes e representados no Brasil.

Palavras-chave: representação, partidos políticos, responsividade, accountability

The representative democracy in Brazil: problems and questions

ABSTRACT: The objective of this work is to bring to the agenda a discussion covering the recent literature on political representation and all its aspects, specifically focusing on the Brazilian case. In terms of methodology, the article is mostly qualitative, seeking to gather many thoughts about the same theme: representation. The findings show that the Brazilian representative democracy has a number of problems, but that much has been achieved since the return to democracy in the eighties, requiring therefore more attention to the relationship between representatives and represented in Brazil.

Keywords: representation, political parties, responsiveness, accountability

\section{INTRODUÇÃO}

A escolha de representantes é utilizada desde o século XVIII em maior escala pelas sociedades que durante os anos seguintes se estabeleceram como democracias e se complexificaram econômica, social e politicamente. Por meio da representação, os cidadãos escolhem pessoas que levarão suas demandas para um outro nível, onde essas preferências são discutidas e podem ser tornadas agenda governamental ou não.
É notória a relevância das instituições representativas e elas permeiam a vida de qualquer cidadão, mesmo que não saibam. Desde as eleições para o Governo Federal até a escolha de um síndico, a necessidade de haver representantes é imanente.

Com as constantes mudanças sofridas pela humanidade pós-segunda guerra, o governo representativo também foi atingido por essa torrente de transformações. Mas será que a representação acompanhou a evolução da sociedade contemporânea? 
Recentemente tem se falado em crise da representatividade, na necessidade de novos meios de democracia, de participação dos indivíduos na política. A discussão é extensa e tem diferentes vertentes e abordagens.

Este trabalho visa apontar alguns dos tópicos do debate levando em consideração o caso brasileiro. O Brasil passa por uma redemocratização - processo iniciado nos anos oitenta após o fim de uma ditadura que durou mais de duas décadas -, que ainda passa por algumas dificuldades. A questão da representação parece problemática no caso brasileiro, e consequentemente, digna de debate.

A primeira parte deste estudo contém uma pequena revisão literária acerca do sistema democrático e da democracia representativa em si. A segunda trata principalmente dos problemas da representação no Brasil relacionados com trabalhos relevantes sobre o tema. Por fim, algumas considerações finais sobre o que foi apresentado nas duas seções supracitadas.

\section{PROBLEMATIZANDO A DEMOCRACIA RE- PRESENTATIVA CONTEMPORÂNEA}

Antes de iniciar a conceituação do que é uma democracia representativa propriamente dita, se faz necessário entender que os regimes democráticos são considerados em termos procedimentais, ao contrário de alguns autores que defendem a indispensabilidade de meios mais participativos de tomadas de decisões para a população e, portanto, de uma concepção mais substantiva de democracia (PATEMAN, 1976; ROUSSEAU, 1987).

Schumpeter (1984) modificou o entendimento do conceito de democracia ao tra- zer uma definição instrumental da mesma. A Doutrina Clássica da Democracia - fusão do pensamento de vários teóricos anteriores - estaria equivocada pelo fato de termos recorrentes da Teoria Democrática do século XVIII, como Bem Comum e Vontade Geral, não existirem na realidade. Além disto, a natureza humana na política seria marcada por apatia e desinteresse do cidadão médio. $O$ termo cidadão médio ou mediano é utilizado neste artigo como a maior parte do eleitorado, que não se sente atraído por nenhum extremo da esfera ideológica e não tem um interesse elevado em política. Então, no final das contas: "o método democrático é aquele acordo institucional para se chegar a decisões políticas em que os indivíduos adquirem o poder de decisão através de uma luta competitiva pelos votos da população" (SCHUMPETER, 1984, p. 336). Conforme o referido autor, em síntese, caberia aos cidadãos escolherem seus representantes por meio de eleições e este seria o único papel da população na política, excetuando os políticos, obviamente.

Przeworski (1999) defende a concepção introduzida por Schumpeter de uma forma mais complexa e elaborada. Para ele, uma definição minimalista de democracia é o suficiente, mesmo que a racionalidade, a representação e a igualdade não sejam plenamente alcançadas. $O$ fato de haver eleições regulares e alternância de poder sem derramamento de sangue já deve ser louvado. Claro que aspectos econômicos e institucionais impactam. Por exemplo, o autor explica que países mais ricos e sistemas parlamentaristas tendem a aumentar a durabilidade de uma democracia. Mas, as bases de um regime democrático são as eleições e a possibilidade de troca de governantes. 
Existem autores procedimentalistas que vão além de uma definição mínima, argumentando não ser suficiente para abarcar todas as características de uma democracia. Mainwaring, Brinks e Liñán (2001) explanam que as concepções de Schumpeter e Przeworski não chegam nem a ser mínimas, mas submínimas. Uma democracia deveria ter quatro particularidades básicas: (a) promoção de eleições competitivas livres e limpas para o Legislativo e o Executivo; (b) o direito de voto deve ser extensivo à grande maioria da população adulta; (c) proteção dos direitos e liberdades civis e políticas dos cidadãos e (d) os governos eleitos de fato governem e não sofram forte influência de militares e outros grupos externos.

Já Dahl (1989) alega que democracias não existem de fato, no máximo existem poliarquias. Num continuum entre regimes autocráticos e democráticos, as poliarquias se encontrariam próximas dos últimos, devendo ter oito características básicas: (1) todos os indivíduos expressam suas preferências votando; (2) o peso do voto é idêntico para todo cidadão; (3) a alternativa com maior número de votos vence; (4) cada indivíduo pode escolher a sua alternativa preferida e pode votar na mesma; (5) todos os indivíduos possuem informações iguais acerca de todas as alternativas; (6) os políticos com maior número de votos vencem todos os demais; (7) as ordens dos governantes eleitos são executadas e (8) As decisões respeitam as sete condições anteriores e/ou as decisões tomadas são subordinadas àquelas tomadas no período eleitoral.

Principalmente desde o século XVIII, os filósofos e teóricos políticos expressam a necessidade de haver uma representação da população em instâncias governamentais. Todas essas conceituações apresenta- das acima tentam provar que a escolha de representantes por meio de eleições é causa necessária e, às vezes, suficiente para uma democracia. Para Manin (1997), o governo representativo é regido por quatro princípios, formulados no século XVIII e que se institucionalizaram desde então. $O$ primeiro deles exprime que os representantes são escolhidos pelos representados. Mesmo que a população pouco participe da política, afora as eleições e sempre esteja elegendo elites ao poder, o fato de poder substituir os políticos que não a agradou é, em si, importante. Em segundo lugar, os representantes devem conservar uma independência parcial diante das preferências dos eleitores. Um terceiro princípio dos governos representativos é que a opinião pública pode se manifestar independentemente do controle do governo. Para isso ocorrer, as decisões públicas devem ser repassadas com transparência para os cidadãos e os indivíduos necessitam de ter liberdade de expressar suas opiniões políticas. Por fim, a quarta característica manifesta a imprescindibilidade das decisões políticas serem tomadas após debate. Sem a deliberação nos Parlamentos e Assembleias, seria bem mais complicado o processo de tomada de decisões.

Manin (1997) identifica dois momentos em que a democracia representativa parece ter entrado em crise: surgimento dos partidos de massa e o crescente "abismo" entre governantes e governados. Porém, ao analisar os dois tipos tradicionais de governo representativo - parlamentar e democracia de partido - e um novo modelo que parece surgir, a democracia de público, o autor parece negar a crise da representatividade. Isto se dá pela readequação dos quatro princípios a este novo tipo de governo re- 
presentativo, no qual os eleitores não se ligam mais aos partidos, os políticos buscam se comunicar mais diretamente com a população e o parlamento tenta se manter um fórum de debate embora os meios de comunicação em massa ocuparam bastante deste espaço.

Para Castiglione e Warren (2006), a democracia representativa tem três características principais: (a) a representação traz consigo uma relação principal-agent ${ }^{1}$, na qual os representantes tem a exigência de serem responsivos aos representados; (b) a representação tem que ser feita de um modo cujo poder político deve ser exercido de forma responsável e os representantes serem accountables 2 à população; (c) o direito de votar em representantes fornece um meio simples de medir a igualdade política. No entanto, a contribuição principal dos autores é refletir acerca de oito problemas teóricos visando repensar o governo representativo. Nesta reflexão há uma preocupação com a representação como um processo, como uma prática e até mesmo como um relacionamento. Ao passar por estes oito pontos os autores concluíram que o crescimento da representação informal, fenômeno inevitável, pode erodir a igualdade trazida pela representação eleitoral, ocasionando também déficit de accountability.

\footnotetext{
1 Uma relação principal-agent ou principal-agente, é tratada na Ciência Política e na Economia como uma relação hierárquica entre o principal (o eleitor no caso da representação) e o agente (representantes), na qual o primeiro pode observar apenas parcialmente o comportamento e as ações do último, dada a falta de informação completa e a vontade de ambos em maximizarem seus ganhos.

${ }^{2}$ A noção de accountability será demonstrada mais à frente no texto, de forma pormenorizada.
}

Urbinati e Warren (2008) demonstram a metamorfose do conceito de representação na contemporaneidade. Pode-se começar pela diversidade de instituições transnacionais ou até mesmo não-territoriais que abarcam os indivíduos e os fazem se sentirem representados por essas organizações. Os autores também expõem a incapacidade dos partidos políticos de continuarem como agregadores e portadores das preferências da população. Portanto, a representação puramente eleitoral passa por limitações e por isso foi notada uma evolução dos representantes dos cidadãos, principalmente após a inclusão de minorias e das mulheres no jogo político, assim como de pautas pósmaterialistas na arena decisória.

Urbinati (2013) continua a discussão sobre democracias de audiência (de público), termo introduzido por Manin (1997), reforçando a ideia de declínio dos atores políticos e ressaltando o valor dos meios de comunicação neste modelo de regime democrático. A autora aponta que os líderes se tornam mais observáveis pela população, dada a vasta exposição que sofrem, mas, em contramão, o sistema tende a ser mais corrupto e a estética fica mais em voga na opinião pública do que a real compreensão das propostas e participação da população. $\mathrm{Na}$ realidade, as eleições acontecem basicamente focadas na imagem dos candidatos e as plataformas são praticamente esquecidas.

\section{3 (OS PROBLEMAS) DA DEMOCRACIA RE- PRESENTATIVA NO BRASIL}

Principalmente desde as manifestações ocorridas em 2013 alguns setores da mídia e da academia vêm levantando a ideia de uma crise de representatividade em solo 
brasileiro. Apesar de ser uma democracia jovem, tendo sido estabelecida no final dos anos 80, o Brasil já parece sofrer com um grande desgaste das instituições representativas e dos representantes perante a sociedade civil. Provavelmente, se as eleições não fossem obrigatórias, uma parcela considerável do eleitorado não compareceria às urnas. Como esse fenômeno (déficit de representação) ocorre no Brasil? O cenário é tão pessimista assim? Uma tentativa de apontar esses problemas e fazer reflexões acerca dessas questões será apresentada no restante do trabalho.

Por exemplo, se a confiança nas instituições for levada em consideração, pode-se constatar que instituições políticas sempre são mal avaliadas, ocupando as últimas posições na avaliação dos cidadãos. O Índice de Confiança Social medido pelo Instituto Brasileiro de Opinião Pública e Estatística (IBOPE) avalia 18 instituições desde 2009, entrevistando uma amostra considerável da população brasileira em todo o território nacional. Pode-se observar a acentuada queda das instituições em 2013, período em que ocorreram as grandes manifestações de rua, na Figura 1.

Figura 1 - Índice de Confiança Social (2009-2014)

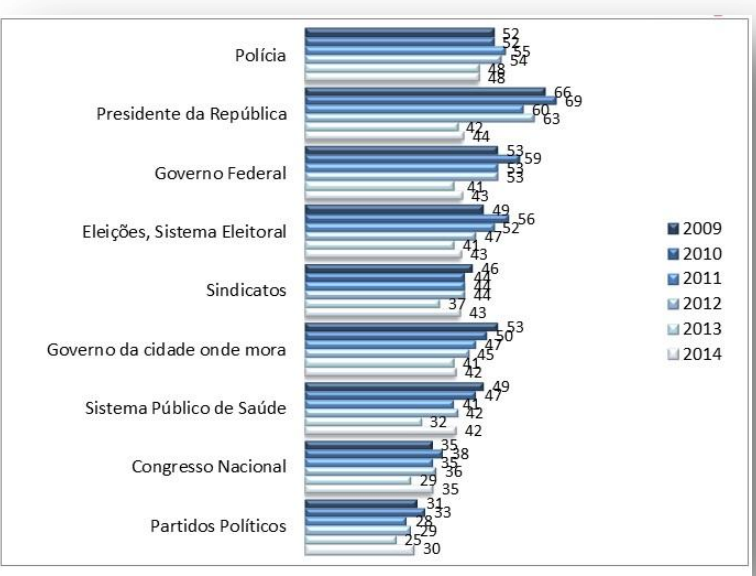

Fonte: IBOPE (2013)
Pelos números é possível inferir que os órgãos representativos têm estima baixa junto aos cidadãos, principalmente o Congresso Nacional e os partidos políticos. Também se faz pertinente constatar que houve uma queda relevante da aprovação da Presidência da República e do Governo federal. Todavia, o que faz essas instituições estarem com tão pouco apreço da sociedade civil?

Para Manin, Przeworski e Stokes (1999), a representação se dá em duas formas: pelo mandato e pela accountability. No geral, a primeira relação, a de representação por mandato, concebe a eleição como a emulação de uma assembleia na qual os eleitores escolhem os partidos ou candidatos cujas propostas mais os agradam. Já na perspectiva da accountability, as eleições funcionam como mecanismos para responsabilizar os governantes a respeito de suas ações. No entanto, essas duas perspectivas podem ser problemáticas, pois os políticos podem possuir objetivos e informações diferentes dos demais cidadãos. Dessa forma, os governantes ao serem eleitos podem tomar decisões voltadas para interesses próprios.

O estudo de Mair (2009) pode ajudar a solucionar o que ocorre com os partidos nesta metamorfose da democracia representativa. Desde o final do século XX os partidos políticos são ineficazes em seu papel intermediário entre representantes e representados, esta função articuladora mais a atribuição de organizar o jogo político e as preferências e programas eram o que tornava esses grupos políticos tão importantes para o governo representativo. Mas parece perceptível que os partidos perderam uma parcela considerável da representatividade, fazendo com que a população escolhesse Organizações Não-Governamentais (ONGs) 
e grupos de interesse para representá-la. Então, essas organizações buscaram se modificar, dando mais ênfase aos líderes e perdendo bastante da ideologia e rigidez programática.

No Brasil pós-ditadura, os recém-criados partidos precisaram se adaptar ao grande montante de eleitores presentes no centro do espectro ideológico, por isso, um alto número de legendas se tornou ou assumiu o papel de partidos catch-all (KIRCHHElMER, 1966), que visam apenas às vitórias nas eleições atraindo a maior quantidade de eleitores possíveis, além de perderem muito do conteúdo programático, modificando os programas e diretrizes partidárias a cada pleito. Mair (2009) defende que a capacidade dos partidos em governar depende da competência em acatar as demandas da população. A necessidade de ser responsivo é imanente às democracias representativas e se os partidos não conseguem ser bem-sucedidos nessa atribuição, por conseguinte perdem a legitimidade representativa.

Essa perda de legitimidade também pode estar intimamente ligada aos recorrentes casos de corrupção no cenário brasileiro. Já que a mídia é tão importante nas democracias de audiência, os partidos e representantes se tornam mais responsáveis junto à sociedade, pelo menos neste sentido específico. Os governantes devem ser responsabilizados por suas ações, contribuindo para o controle por parte dos cidadãos. Um representante accountable tem bem mais chances de fazer um bom governo. Mair (2009) aponta que o que não pode ocorrer é um distanciamento da capacidade em atender as preferências dos eleitores e a accountability (responsabilidade).
Mas o que é accountability afinal? $\underline{\text { Pinho }}$ e Sacramento (2009) fazem o esforço de tentar compreender o significado desta palavra, traduzida e interpretada de várias formas pelos cientistas sociais brasileiros. No final das contas, os autores constatam que o significado do conceito engloba: "responsabilidade (objetiva e subjetiva), controle, transparência, obrigação de prestação de contas, justificativas para as ações que foram ou deixaram de ser empreendidas, premiação e/ou castigo" (PINHO; SACRAMENTO, 2009, p. 22).

Contudo, ainda é um termo em construção no Brasil. Vinte anos ainda não foram suficientes para a institucionalização do termo. Para este trabalho, accountability será entendida como a responsabilização dos governantes e agentes públicos pelos seus atos na administração.

O'Donnell (1998) propõe que diferenciemos a accountability em duas vertentes: vertical e horizontal. A primeira concerne ao poder que os eleitores têm através do voto em premiar ou punir os políticos nos pleitos, de forma retrospectiva ou prospectiva. O âmbito horizontal é tipificado pela existência de instituições de controle que supervisionam, emitem pareceres ou até mesmo punem outras agências. Alguns autores indicam haver uma accountability societal (ou social) (PERUZZOTTI; SMULOVITZ, 2002; O'DONNELL, 2002), que é considerada uma expansão da vertical no sentido de ser concebida por meio de associações, movimentos sociais e a mídia, objetivando pressionar o governo, expor seus erros e consequentemente pedir melhorias em suas ações.

Assim como Mair (2009), Arato (2002) também salienta a importância da accountability para a democracia representativa. 
Para o autor a responsabilização dos representantes pelo eleitorado é fator primordial de um regime democrático, pelo fato de um controle dos governantes por parte da população restringir o comportamento e também punir ou recompensá-los de acordo com suas ações. Refletindo sobre a avaliação retrospectiva de representantes em solo brasileiro, não é possível dizer que ela aconteça com muita frequência. Primeiramente, a maioria dos eleitores, após um curto período de tempo, esquecem em quem votaram nas eleições anteriores. Em segundo lugar, os representantes utilizam de práticas clientelistas, legais (pork barrel ${ }^{3}$ e patronagem ${ }^{4}$ ) e ilegais (compra de votos), para manter o apelo eleitoral. Desse modo, a população reclama constantemente dos políticos e de suas ações, mas o próprio desinteresse ou desconhecimento da mesma criam um ciclo vicioso nos períodos eleitorais, no qual os mesmos maus candidatos se reelegem e continuam atuando de forma que não são responsivos (não atendem as demandas) à população.

As manifestações de 2013 que se estenderam a uma amostra considerável de cidades brasileiras foram importantes para avultar diversas reivindicações, inclusive pósmaterialistas, e pela grande mobilização de pessoas. Mas, na realidade, o grande número de solicitações, fez com que os protestos parecessem difusos e desorganizados - não

\footnotetext{
${ }^{3}$ Pork Barrel é a prática na qual os políticos priorizam ostensivamente o envio de verbas, recursos e políticas públicas para suas bases ou distritos eleitorais, ou seja, focando sua atuação política para os locais que sabe onde têm votos e apoio, desse modo, facilitando sua busca por reeleição.

${ }^{4}$ Patronagem é definida como uma relação clientelista que ocorre quando um político, correligionário ou membro de um partido oferece cargos e/ou favores em troca de apoio político de um terceiro.
}

que isso tire a relevância do acontecido, visto a dificuldade em reunir tantas pessoas apenas por redes sociais para as manifestações. Outro ponto que merece ser tocado é o fato da maioria dos manifestantes serem jovens, universitários ou recém-formados, de classe média. Entretanto, será que a parcela da população em maior vulnerabilidade socioeconômica teve suas propostas externadas?

O que esses protestos igualmente demonstraram foi o cansaço da população com os representantes e instituições políticas do país. A proposta de uma reforma política ficou mais perto de sair do papel e os governantes pareceram se assustar com a grande mobilização. Todavia, alguns meses após as manifestações, o cenário havia se normalizado e nas eleições do ano seguinte houve pouca renovação nas assembleias estaduais e no Congresso Nacional. A fagulha acesa por essas mobilizações não foi aproveitada, tanto por desinteresse dos representantes, satisfeitos com o status quo, quanto por igual desentusiasmo da população, que não conseguiu se organizar e fazer pressão efetiva.

\section{CONSIDERAÇÕES FINAIS}

Durante este trabalho os problemas da democracia representativa no Brasil foram apontados, como deve ser possível apreender no decorrer do texto. Este ensaio foi feito deste modo justamente para salientar as vicissitudes que afligem a representação em território brasileiro e solapam a qualidade democrática no país. Nenhuma solução foi proposta anteriormente visando relacionar a literatura apresentada com as dificuldades vividas pelo governo representativo no Brasil. A corrupção endêmica, a 
falta de responsiveness ${ }^{5}$, a deficiência dos mecanismos de accountability vertical e a incapacidade dos partidos de serem os intermediários entre representados e representantes evidenciam as razões da baixa aprovação das instituições representativas e dos governantes.

Manin, Przeworski e Stokes (1999) explicam que os cidadãos talvez possam ser capazes de controlar os representantes se os últimos souberem que terão de prestar contas de seus atos. Governos accountable são aqueles em que os cidadãos podem discernir se os agentes públicos estão ou não fazendo seu papel de forma correta. Assim, os que agem de acordo com o interesse público são reeleitos, os que não possuem uma boa conduta, não o são. Deste modo, a representação por accountability acontece quando os eleitores votam na manutenção dos representantes que agiram a favor do bem público. Os instrumentos de accountability melhoraram no Brasil nos últimos anos, principalmente por meio de agências fiscalizatórias (Controladoria Geral da União e Tribunal de Contas da União, por exemplo), mas a responsabilização por intermédio das eleições ainda carece de evolução. Como dito anteriormente, a população brasileira é conivente com políticos pouco responsivos em períodos eleitorais, não utilizando a avaliação retrospectiva e mantendo o desinteresse por política em níveis altíssimos.

Os partidos e representantes também faIham ao estarem acomodados com o status quo e práticas clientelistas. Além disto, a

\footnotetext{
${ }^{5}$ Responsiveness ou responsividade é a capacidade dos governantes ou qualquer outro agente público em atender as demandas da população. Se um governo é responsivo, então ele cumpre com as atribuições pelas quais foi eleito
}

maioria dos políticos não é responsivo, deixando as propostas de campanha para trás, e, por conseguinte, não atendem as demandas da população. Destarte, em algumas situações, os representantes não são nem responsivos, nem responsáveis.

Com todos esses problemas postos em discussão, pode-se concluir que existe uma crise de representatividade no Brasil, assim como existem em vários outros países. Se existissem mais meios deliberativos e participativos a população talvez conseguiria criar uma cultura política mais robusta e o interesse pela política aumentaria. No entanto, apenas suposições podem ser feitas. Muitos autores tratam das metamorfoses e crises da representação com propriedade, porém, como Manin (1997) argumentou, os regimes democráticos atuais se tornaram democracias de público e os governos representativos passam por certas dificuldades, mas estão se readaptando a este novo modelo e respeitam os quatro princípios necessários à representação propostos pelo autor.

Para exemplificar a importância da representação pode-se pensar num cenário em que as manifestações de 2013 seriam mais organizadas e com demandas bem definidas. Neste panorama se faz justo supor que surgiriam líderes e porta-vozes dentro da mobilização. Então, se o movimento quisesse transformar suas preferências em agenda política poderia apoiar uma ou mais dessas lideranças nas eleições. 0 mesmo ocorre com as minorias, principalmente o movimento LGBT que se encontra sub-representado em todas as instâncias federais, impossibilitado de exercer uma pressão relevante nos meios de tomada de decisão. Estes exemplos demonstram que a representação, ainda que se adaptando a 
contemporaneidade e sendo constantemente criticada e posta à prova, ainda é a forma mais eficaz de participar do jogo político e de se "fazer" democracia.

Por fim, para estudos futuros, parece importante estudar o efeito que os partidos políticos têm na democracia representativa brasileira. O foco deste artigo foi a representatividade em si, mencionando apenas marginalmente o papel dos partidos. Trabalhos sobre o tema já foram feitos (MAIR, 1994; WATTENBERG, 2000), mas focam os países ocidentais desenvolvidos ou generalizam o fenômeno do declínio da representação por meio dos partidos políticos. Talvez um trabalho especificamente sobre o Brasil possa apontar diferenciações em relações a outras nações, além de trazer uma análise realista e original do que ocorre aqui.

\section{REFERÊNCIAS}

ARATO, A. Representação, soberania popular, e accountability. Lua Nova, n. 55-56, p. 85-103, 2002.

CASTIGLIONE, D.; WARREN, M. E. Rethinking democratic representation: eight theoretical issues. In: CENTRE FOR THE STUDY OF DEMOCRATIC INSTITUTIONS. Rethinking Democratic Representation. University of British Columbia, maio, 2006. p. 20.

DAHL, R. Um prefácio à teoria democrática. Rio de Janeiro: Zahar, 1989.

IBOPE. Após queda acentuada em 2013, Índice de Confiança Social se estabiliza. Rio de Janeiro, ago. 2013. Disponível em: <http://www.ibope.com.br/pt-br/noticias/ Paginas/Ap\%C3\%B3s-queda-acentuada-em2013,Indice-de-Confianca-Social-se-estabili za.aspx>. Acesso em: 25 jun. 2015.
KIRCHHEIMER, Otto. The transformation of the Western European Party System. In: LAPALOMBARA; WINER, M. Political Parties and Political Development. Princeton: Princenton University Press, 1966.

MAINWARING, S.; BRINKS, D.; LIÑÁN, A. P. Classificando regimes políticos na América Latina, 1945-1999. Dados, v. 44, n. 4, p. 645-687, 2001.

MAIR, P. Representative versus responsible government. Max Planck Institute for the Study of Societies Working Paper, v. 9, n. 8, p. 19, set. 2009.

P. Party organizations: from civil society to the state. In: KATZ, R.; MAIR, P. How Parties Organize. London: SAGE, 1994. MANIN, B. The principles of representative government. London: Cambridge University Press, 1997.

MANIN, B.; PRZEWORSKI, A.; STOKES, S. Eleições e representação. Lua Nova: revista de cultura e política, n. 67, p. 105-138, 1999.

O'DONNELL, G. Accountability horizontal e as novas poliarquias. Lua Nova, n. 44 , p. $28-$ 52, 1998.

G. Acerca de varias accountabilities y sus interrelaciones. In: PERUZZOTTI, E; SMULOVITZ, C. Controlando la Política. Buenos Aires: Temas, 2002.

PATEMAN, C. Participation and democratic theory. London: Cambridge University Press, 1976.

PERUZZOTTI, E.; SMULOVITZ, C. (ed.). Controlando la política: ciudadanos y medios en las nuevas democracias latinoamericanas. Buenos Aires: Temas, 2002.

PINHO, J. A. G. de; SACRAMENTO, A. R. S. Accountability: já podemos traduzi-la para o português?. Revista de Administração Pública, Rio de Janeiro, p. 1343-1368, nov./dez. 2009. 
PRZEWORSKI, A. Minimalist conception of democracy: a defense. In: SHAPIRO, I.; HACKER-CORDÓN, C. Democracy's Value. London: Cambridge University Press, 1999. p. 23-55.

ROUSSEAU, J.-J. Do Contrato Social. São Paulo: Nova Cultural, 1987.

SCHUMPETER, J. A. Capitalismo, Socialismo e Democracia. Rio de Janeiro: Zahar, 1984.

URBINATI, N.; WARREN, M. E. The concept of representation in contemporary democratic theory. Annual Review of Political Science, v. 11, p. 387-412, 2008.

URBINATI, N. Crise e metamorfoses da democracia. RBCS, v. 28 , n. 82 , p. 5-16, jun. 2013.

WATTENBERG, M. P. The decline of party mobilization. In: DALTON, R; WATTENBERG, M. P. Parties without partisans. Oxford: Oxford University Press, 2000.

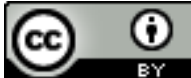

License information: This is an openaccess article distributed under the terms of the Creative Commons Attribution License, which permits unrestricted use, distribution, and reproduction in any medium, provided the original work is properly cited.

Artigo recebido em 09 de outubro de 2015.

Avaliado em 24 de fevereiro de 2016.

Aceito em 23 de março de 2016.

Publicado em 25 de maio de 2016.

Como citar este artigo (ABNT):

MACHADO, Audálio José Pontes. A Democracia Representativa no Brasil: problemas e questionamentos. Estação Científica (UNIFAP), Macapá, v. 6, n. 1, p. 09-18, jan./abr. 2016. 